\title{
Relationship between Elder abuse, Life Satisfaction and Individual and Social Variables among Elderly Referred to Health Centers in Rafsanjan
}

\author{
Akbari. $A^{1}$ \\ ${ }^{*}$ Assar. $\mathrm{Sh}^{2}$ \\ Hosseini. $F^{3}$ \\ 1- MSc in Nursing, Instructor, \\ Medical-Surgical Nursing \\ Department, Geriatric Care \\ Research Center, Faculty \\ of Nursing and Midwifery, \\ Rafsanjan University of Medical \\ Sciences, Rafsanjan, Iran. \\ 2- ( ${ }^{*}$ Corresponding Author) \\ Ph.D. in Microbiology, \\ Microbiology Department, \\ Geriatric Care Research Center, \\ Rafsanjan University of Medical \\ Sciences, Rafsanjan, Iran. \\ Email: assar_sh@yahoo.com; \\ assar_sh@rums.ac.i \\ 3- Ph.D. Student of Nursing, \\ Geriatric Care Research Center \\ Rafsanjan University of Medical \\ Sciences, Rafsanjan, Iran.
}

\begin{abstract}
Introduction: Elderly people are vulnerable groups in society and the phenomenon of elder abuse is one of the main challenges in caring and protecting the elderly.

Objective: The present study was conducted to determine the prevalence of abuse and its relationship with life satisfaction in the elderly.

Materials and Methods: This cross-sectional study was performed on the elderly referred to health centers in Rafsanjan. The Elder Abuse Questionnaire, demographic information and life satisfaction questionnaire were used for data collection. Data were analyzed using descriptive and analytical statistics and a p-value was considered less than 0.05 which is statistically significant.
\end{abstract}

Results: The mean age of the elderly was 63 years of age. The lowest and the highest prevalence were related to physical abuse (3\%) and to financial abuse, respectively $(76 \%)$. Further, there was a significant relationship between abuse and illness, disability, marriage, income and life satisfaction of the elderly.

Discussion and Conclusion: Elderly had experienced different types of abuse, especially financial abuse, and there was a relationship between elderly and their life satisfaction.

Keywords: Elder Abuse, Elderly, Life, Satisfaction. 


\section{ارتباط سالمند آزارى و رضايت از زندكى و متغيرهاى فردى و اجتماعى در بين سالمندان مراجعه كننده به مراكز بهداشتى شهرستان رفسنجان}

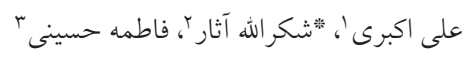

جكيده

مقدمه: سالمندان از جمله كَروهاى آسيبيذير در جامعه مىباشند و پِيده سالمند آزارى از جمله خالشهاى مطرح در حيطه مراقبت و حمايت از سالمندان است. هدف: مطالعه كنونى به منظور تعيين شيوع سوءرفتار و ارتباط آن با رضايت زندكَى سالمندان انجام شد.

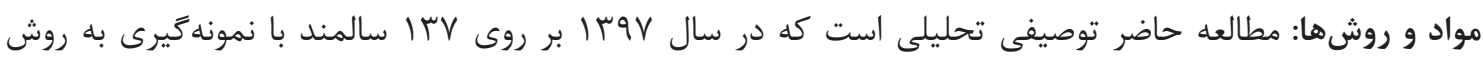
خوشهاى و تصادفى به صورت قرعه كشى انجام شد. از يرسشنامه بررسى سوء رفتار با سالمند، اطلاعات دموكرافيك و

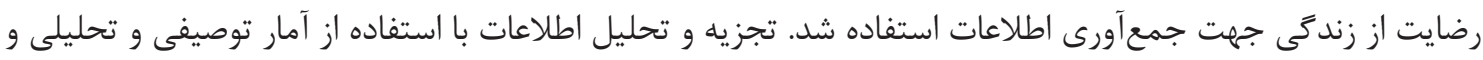

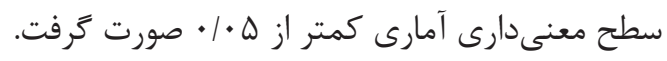

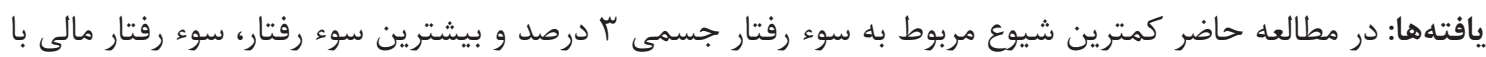

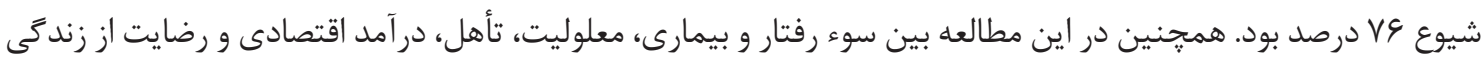
سالمندان ارتباط معنى دارى وجود داشت. بحث و نتيجه كيرى: سالمندان انواع مختلف سوء رفتار خصوصاً مالى را بيشتر تجربه كردند و بين سوء رفتار بار با سالمندان

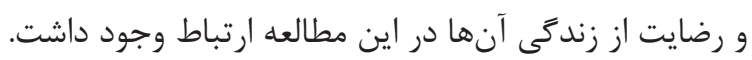

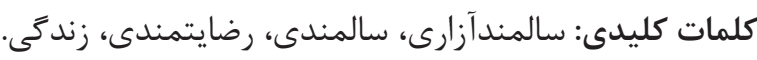

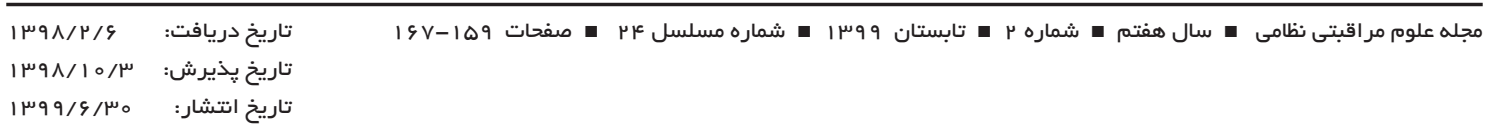

سنتها و باورهاى اصيل و دينى خود دارند. اين امر موجب شده كه مقدمه

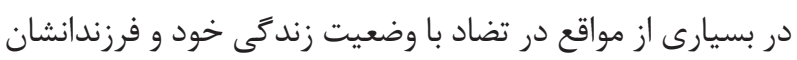
با پِيشرفت بهداشت و ارائهى مراقبتهاى پيشخَيرانه و كنترل

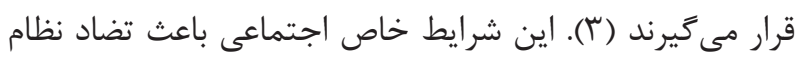

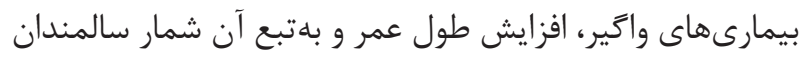

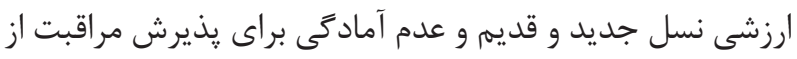

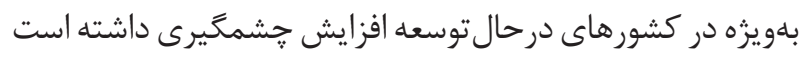
سالمند شده و سبب مى گردد كه وضعيت سالمندان در خانواده

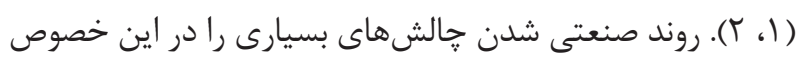

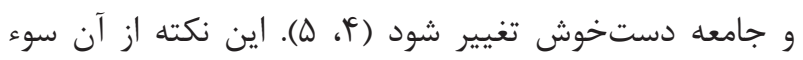

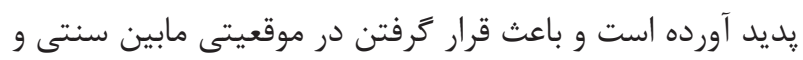

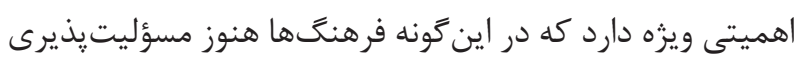

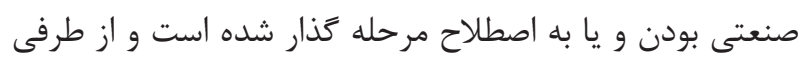

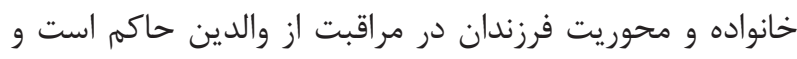
نتيجه آن وجود سوء رفتار نسبت به سالمندان در خانواده است،

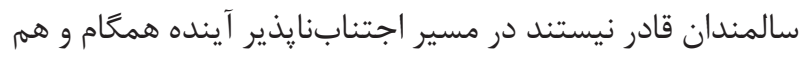

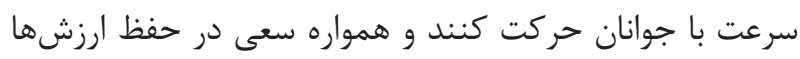


و يا اينكه عدم وجود رضايت از زندكى ممكن است باعث حساس

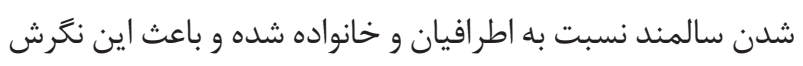

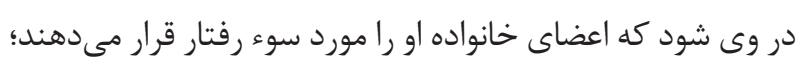

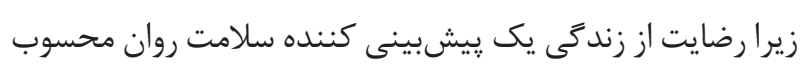

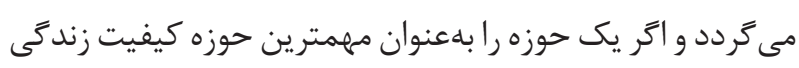

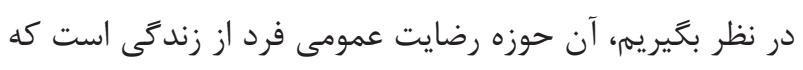

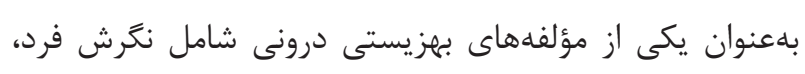

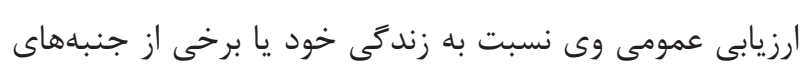

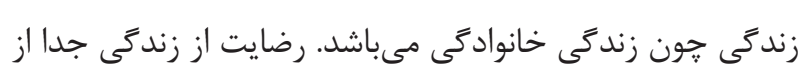

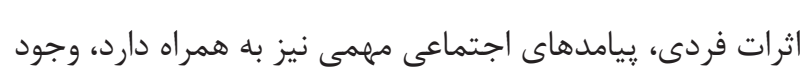

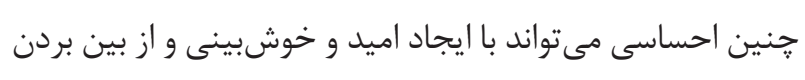

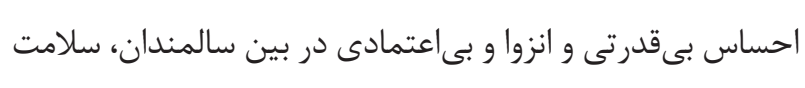
فرد و جامعه را تضمين نمايد و همجنين نارضايتى، در طولانى

مدت مىتواند موجب انزوا و بى اعتمادى اجتماعى شود ( ا ( ). لذا، اين مطالعه جهت آكاهى از ميزان رضايت از زند مَّى سالمندان و ارتباط آن با سوء رفتار سالمندان صورت كرفت تا به يرستاران،

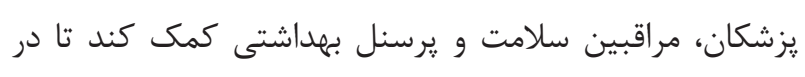
بررسى و مواجهه با اشخاص سالمند، سوء رفتار با سالمندان رانيز مدنظر داشته باشند و با توجه به اين نكته كمك شود تا سالمندان

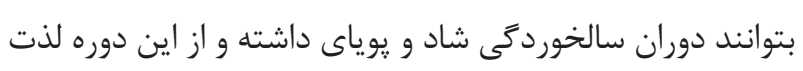
ببرند. بنابراين تحقيق حاضر به بررسى سالمندآزارى و رضايت از

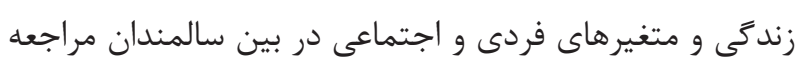
كننده به مراكز بهداشتى شهرستان رفسنجان.

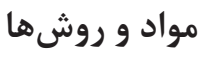

در مطالعه توصيفى -تحليلى حاضر، · · ب نفر از افراد بالاى • • سال

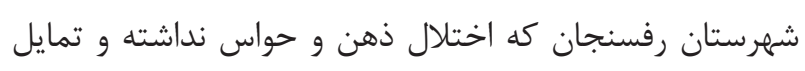

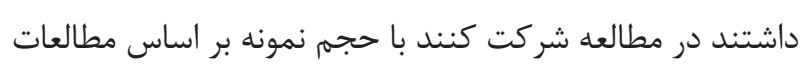

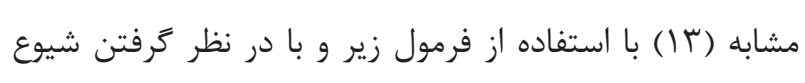

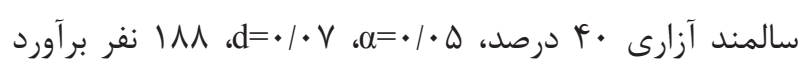

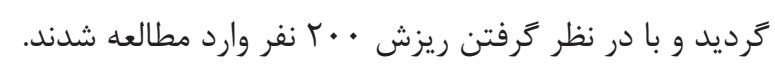
$\frac{}{|8|} \quad n=\frac{\left(Z_{1-\frac{\alpha}{r}}\right)^{r} \cdot p \cdot q}{d^{r}}$
ازجمله يِيامدهاى افزايش تعداد سالمندان در خانواده، مىتوان

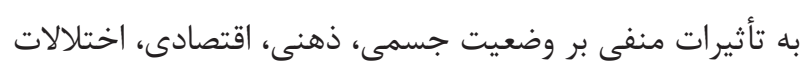
روانى و عاطفى، عدم تحمل بار مسئوليت، خستخى فردى و انزواى إنى

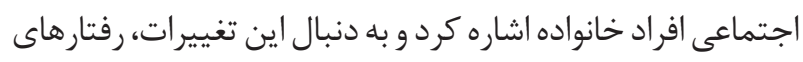
ضداجتماعى و خشونت نسبت به سالمندان افزايشيافته است (ه).

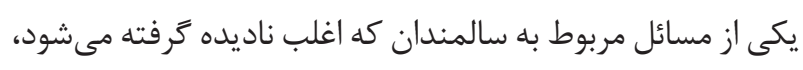

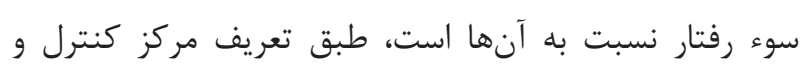

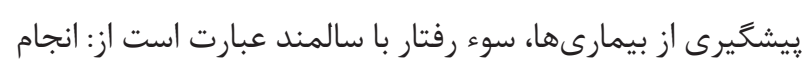

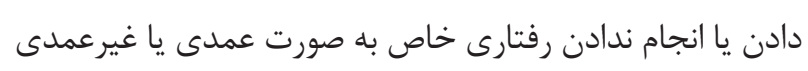

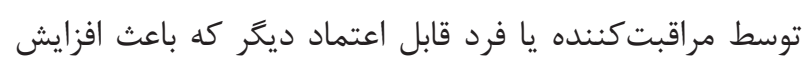

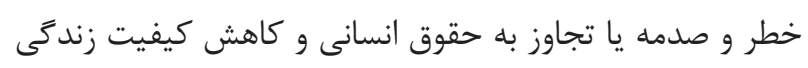

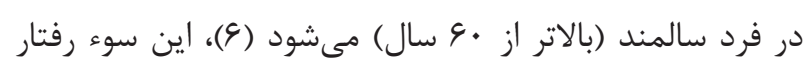
شامل سوءاستفاده فيزيكى، جنسى، روانى عاطفى، غفلت، ترى

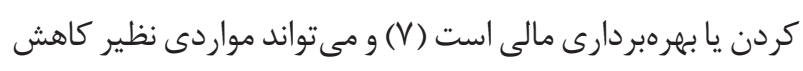

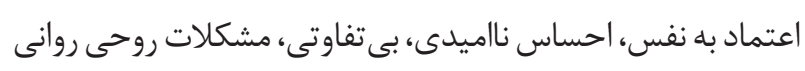

و ناتوانى را براى سالمند در يى داشته باشد (^).

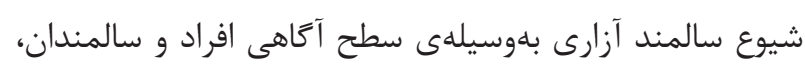

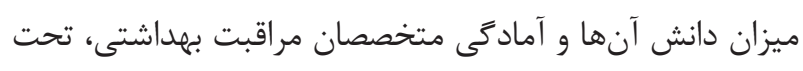

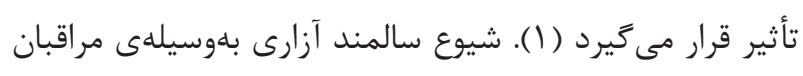

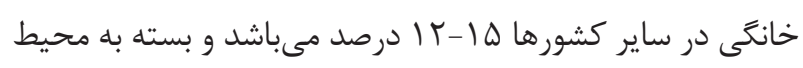

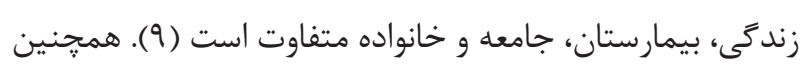

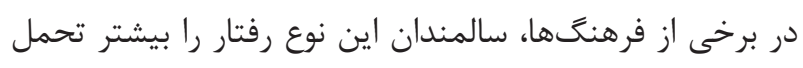

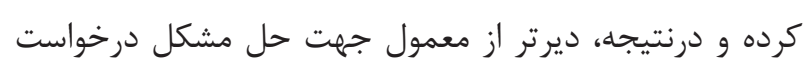

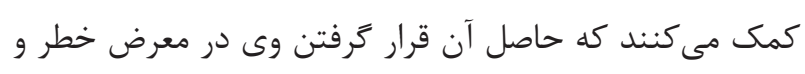

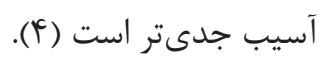
اما يزوهشها در خصوص سالمند آزارى در كشور ما در كلانشهرها

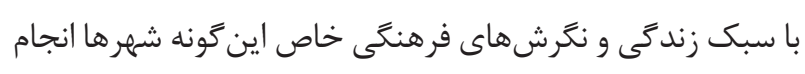

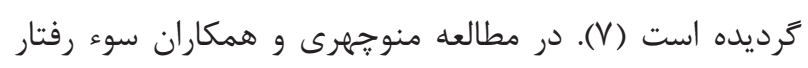

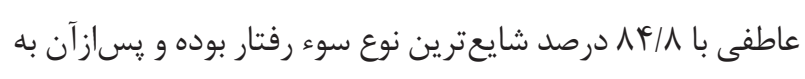

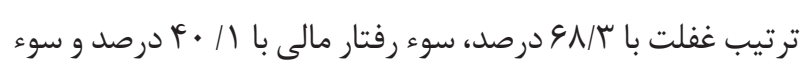

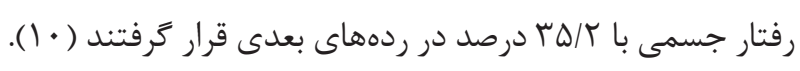

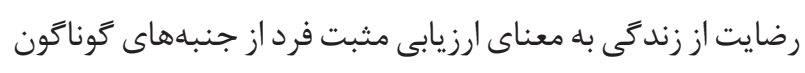

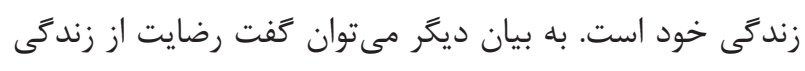

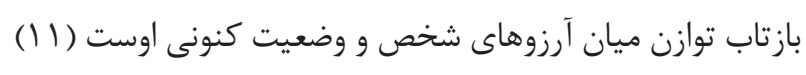


توسط هروى كريموى در سال 91 ا اطراحى شد.زير مقياس هاشامل

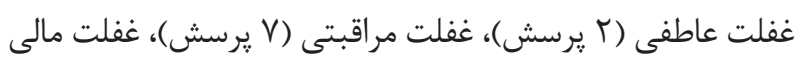

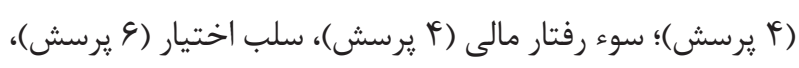

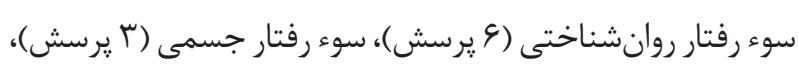

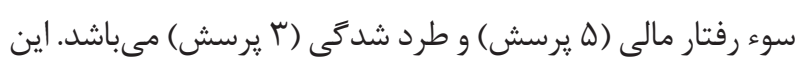
ابزار داراى كزينهاى "بلى"، "خير" و "اموردى ندارده بود. كزينه

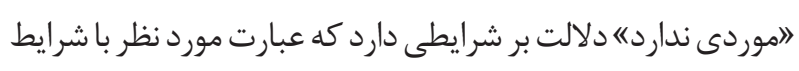

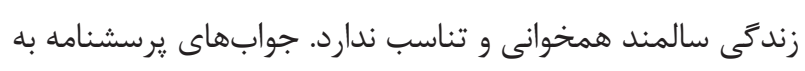

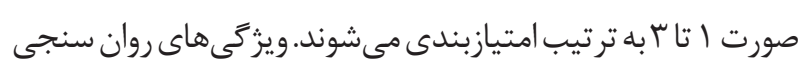

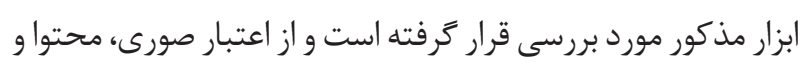
سازه برخوردار است. محاسبه ضريب آلفا كرونباخ سل درصد و و ثبات از طريق آزمون مجدد مؤيد يايايى مطلوب يرسشنامه است (ه (1).

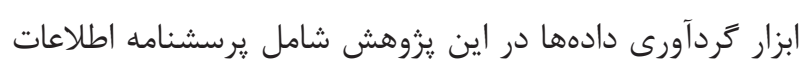

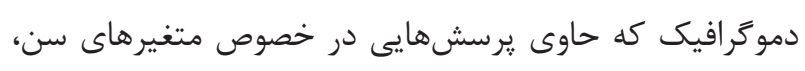

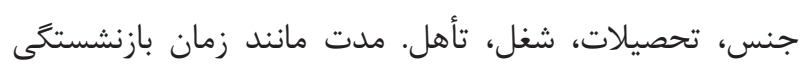

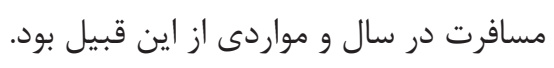
اين مطالعه به تائيد كميته اخلاق دانشعاه علوم يزشكى دونى رفسنجان

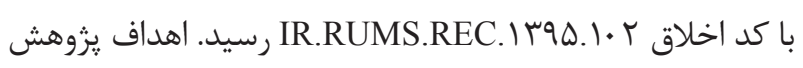
براى سالمندان توضيح داده شد و وِ إن از اخذ رضايت آكاهانه وارد يزوهش شدند. حق خروج در هر زمان از مطالعه براى آنان

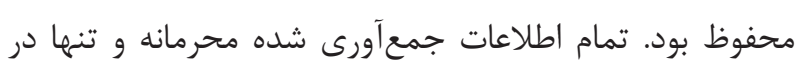

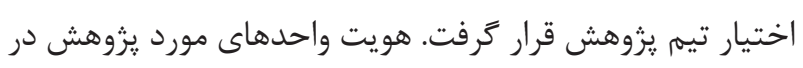

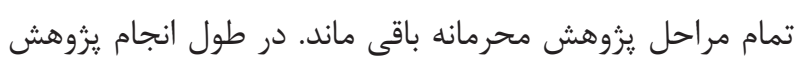

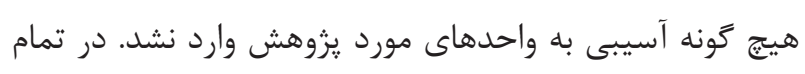

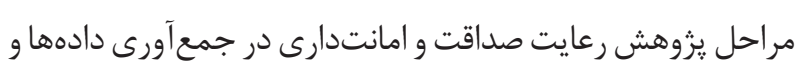

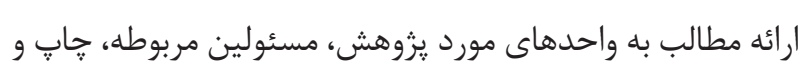

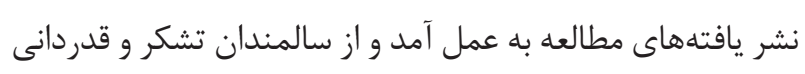

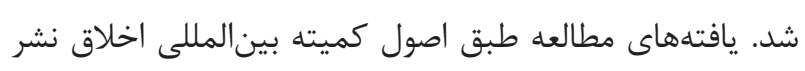

Committee of Publication Ethics (COPE) تجزيه و تحليل دادهها توسط نرمافزار SPSS نسخه ها و با

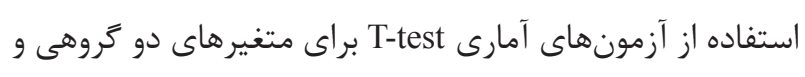
Analysis of Variance (ANOVA)

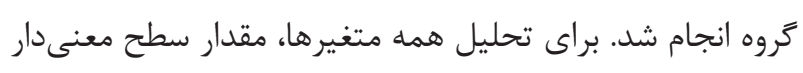

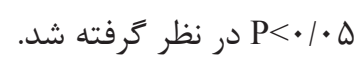

$n=\frac{1 / 99^{r} \times \cdot / 4 \times \cdot / 9}{\cdot / \cdot V^{r}}=111$

نمونهها به شيوه تركيبى و از نمونه كيرى خوشهاى و تصادفى

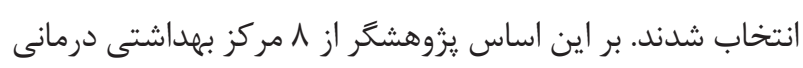
موجود در شهرستان رفسنجان، مراكز جامع خدمات سلامت شماره

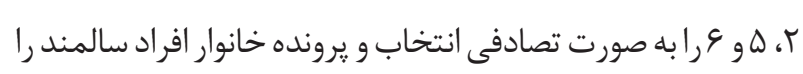

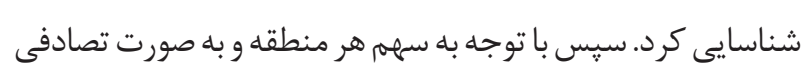

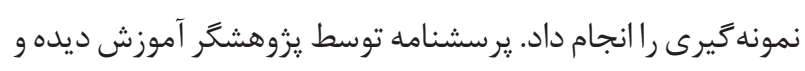

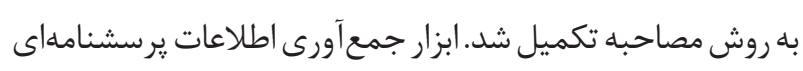

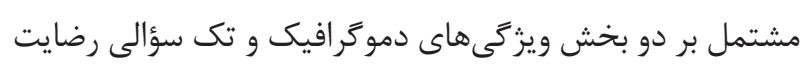

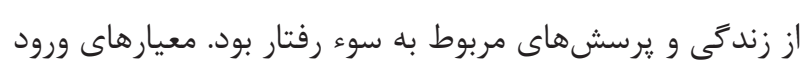

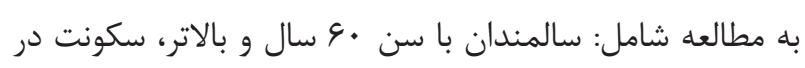

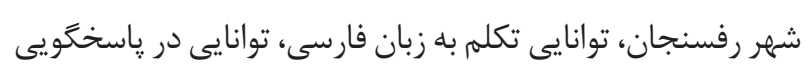

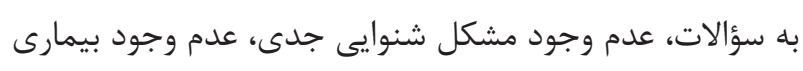

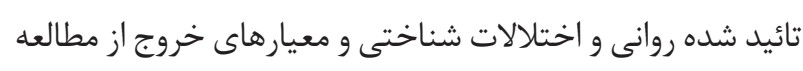

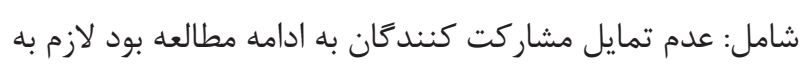

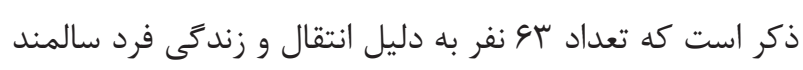

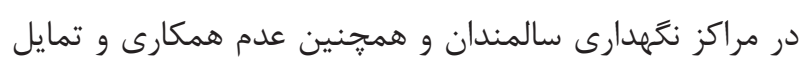
خانواده در حين مصاحبه از مطالعه خارج شدند.

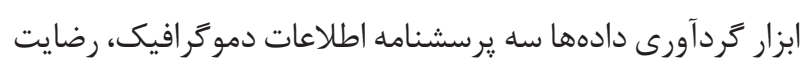

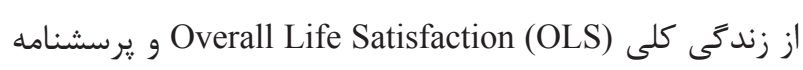
سالمند آزارى بود. يرسشنامه تك گَويهاى رضايت كلى (OLS)

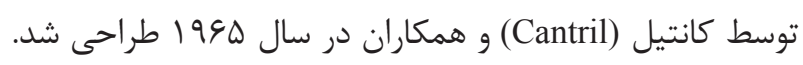
در مقياس تك كويهاى از سالمندان خواسته شد به ميزان رضايت

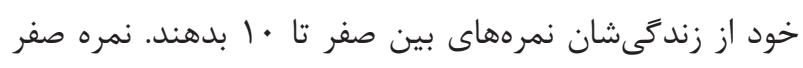

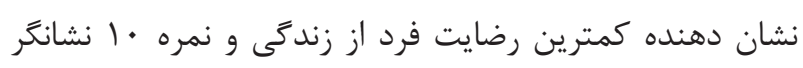

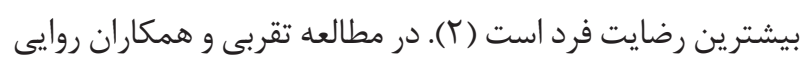

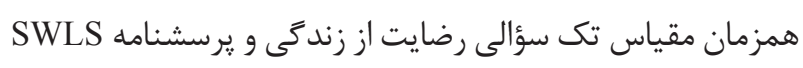
(Satisfaction With Life Scale)

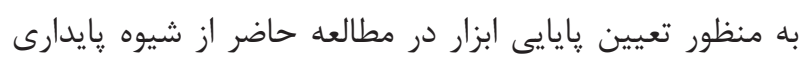

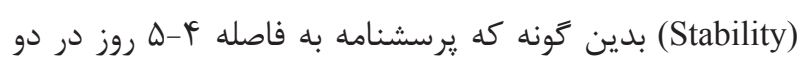

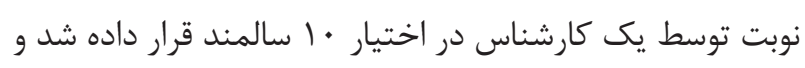

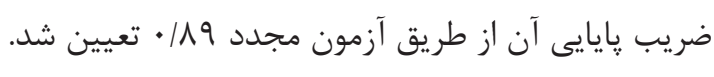

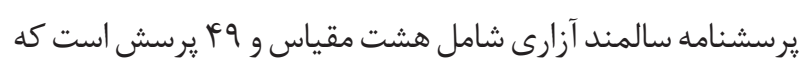


همرجنين جهت سنجش سالمند آزارى با متغير هاى مانند جنسيت،

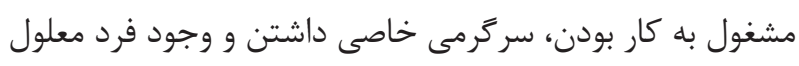

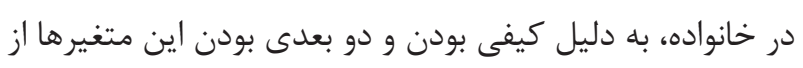

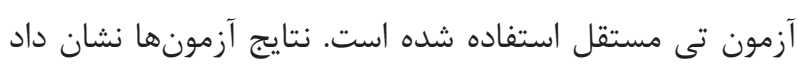

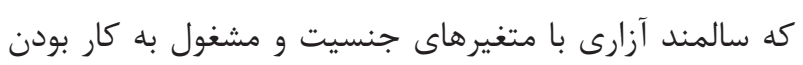
رابطه معنى دارى ندارد، ولى با متغيرهاى سركرمى خاصى داشتن و وجود فرد معلول در خانواده رابطهى معنى دارى دارد (جدول با ؟).

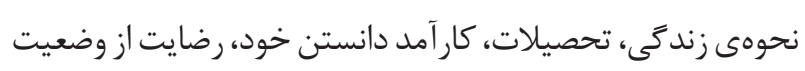

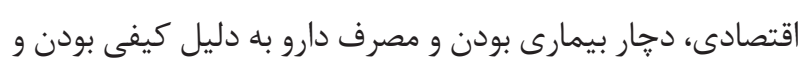

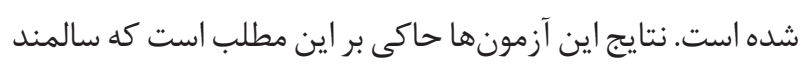

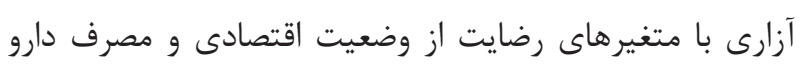

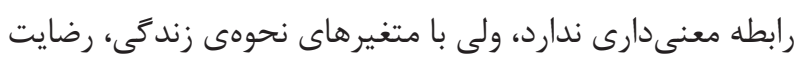

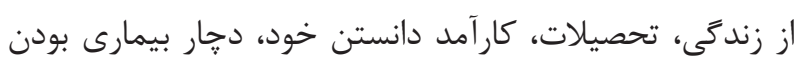
رابطهى معنى دارى دارد (جدول ع). جهت سنجش ارتباط سالمند آزارى با متغيرهاى وضعيت تأهل،

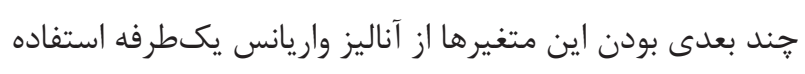

يافتنه ها

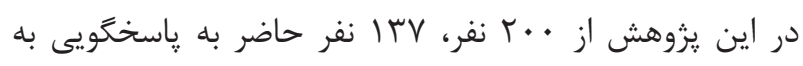

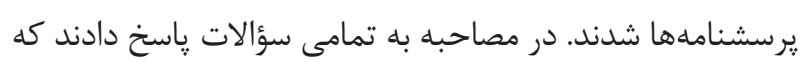

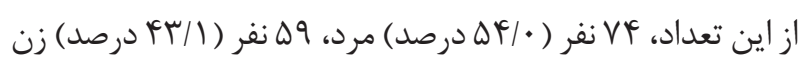

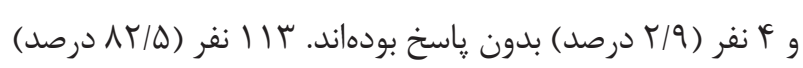

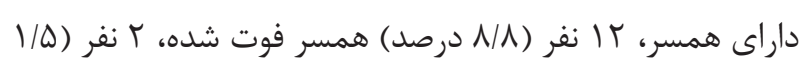
درصد) مطلقه و 9 نفر (9/9 درصد) بدون گاسخ بودهاند. همجنين

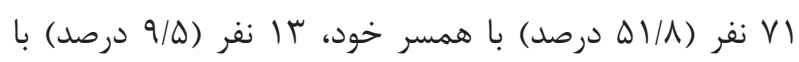

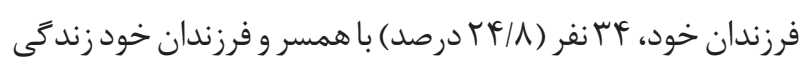
مى كنند و 19 نفر (1/9/9 درصد) بدون گِاسخ بودهاند (جدول (). از بين ابعاد سوء رفتار در سالمندان، بيشترين ميزان سوء رفتار مربوط به سوء رفتار مالى و كمترين ميزان مربوط به سوء رفتار جسمى بود. همجنين ميزان سالمند آزارى و رضايت زندگى، در سالمندان متأهل، كسانى كه با همسر خود زند گىى مى كردند، سطح

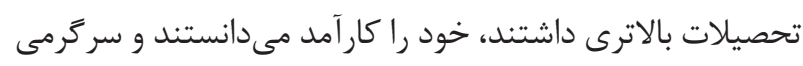
خاصى داشتند كمتر بود (جدول ب).

جدول ا - مشخصات دمو

\begin{tabular}{|c|c|c|c|}
\hline درصد & فراوانى & & \\
\hline$F+/ l$ & $\Delta 9$ & زن & \multirow{3}{*}{ جنسيت } \\
\hline$\Delta F$ & $V f$ & 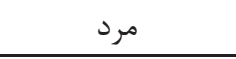 & \\
\hline$r / q$. & f & بدون ياسخ & \\
\hline$\Lambda T / Q$. & $11 \pi$ & داراى همسر & \multirow{4}{*}{ تأهل } \\
\hline$\Lambda / \Lambda$ & it & همسر فوت شده & \\
\hline $1 / 0$ & r & همسر جدا شده & \\
\hline $9 / 9$. & 9 & بدون ياسخ & \\
\hline Tr/A. & me & با همسر و فرزندان & \multirow{4}{*}{ شيوه زندگى } \\
\hline$\Delta / / \Lambda$. & VI & با همسر & \\
\hline $9 / 0$ & Ir & با فرزندان & \\
\hline $1 \pi / 9$. & 19 & بدون קاسخ & \\
\hline$r \varphi / 0$. & $r$. & 1-r-r سال & \multirow{4}{*}{ مدت زمان بازنشستخى } \\
\hline$r q / r \cdot$ & f. & r-9 سال & \\
\hline $19 / \mathrm{V}$ & rV & بيشتر از شش سال & \\
\hline 1.194 & 10 & بدون קاسخ & \\
\hline FN/IV & 99 & $\varphi \Delta_{-} G$. & \multirow{3}{*}{ سن } \\
\hline Fr/Vq & 4 . & $V \cdot .90$ & \\
\hline$N / r$ & 11 & $\Lambda \cdot \_V \cdot$ & \\
\hline
\end{tabular}




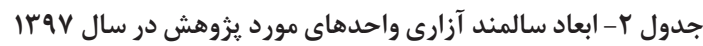

\begin{tabular}{|c|c|c|c|}
\hline فراوانى (درصى ندارد & فراوانى (درصد) & فراوانى (درصد) & زير مقياسهاى \\
\hline $1(\% \cdot / V)$ & $\Lambda \vee(/ .9 \vee)$ & $p q(/ / \% \Delta)$ & عاطفى غفلت \\
\hline$V(/ . \omega)$ & $1 \cdots(/ . V 1)$ & $r \cdot(/ . r 1)$ & غفلت مراقبتى \\
\hline$r(/ .1)$ & $170(/ .91)$ & $1 \cdot(/ . \mathrm{V})$ & غفلت مالى \\
\hline$r(/ .1)$ & $90(1.99)$ & $F \cdot(/ / r q)$ & سلب اختيار \\
\hline$\Delta(/ . \mu)$ & $11 V(/ . \wedge \Delta)$ & $10(\%)$ & سوء_رفتار روانشناختى \\
\hline $1 \cdot(/ . V)$ & ITF $(/ .9 \cdot)$ & $r(/ . r)$ & سوء رفتار جسمى \\
\hline$F(/ . T)$ & $\Delta V(/ . F I)$ & $V \varphi(/ . \Delta \Delta)$ & سوء رفتار مالى \\
\hline$r(\% 1)$ & Vq (/.ఎV) & $\Delta G\left(/ / \|^{\mathcal{C}} \cdot\right)$ & طرد شدگى \\
\hline
\end{tabular}

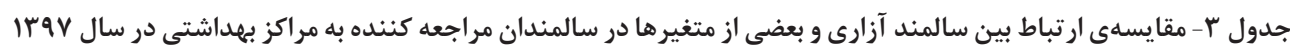

\begin{tabular}{|c|c|c|c|}
\hline $\begin{array}{c}\text { P-Value } \\
\text { One-sample- T test } \\
\end{array}$ & درجه آزادى & آماره آزمون تى & متغير ها \\
\hline$\cdot|q|^{4}$. & IT. &.$/ 4 \& 9$ & جنسيت \\
\hline$\cdot 1 \Delta T$ & 111 & .1940 & اشتغال به كار \\
\hline$>\cdot 1 \cdot \cdots \cdot 1$ & 114 & Mlgpt & داشتن سرگرمى \\
\hline$\cdot 1 \cdot 99$ & 111 & r/99 & رضايت از زندگى \\
\hline r & $1 \cdot 1$ & $-T / T \cdot r$ & داشتن معلوليت \\
\hline
\end{tabular}

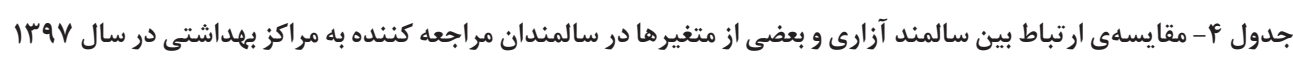

\begin{tabular}{|c|c|c|c|c|c|c|}
\hline P-Value & سطح آماره (F) & ميانگين مربعات & درجه آزادى & مجموع مربعات & & متغير \\
\hline \multirow{3}{*}{$\cdot 1 \cdot 4 q$} & \multirow{3}{*}{$r / 1 \cdot 9$} & $1.99 / 190$ & $r$ & r।qr/Vq. & بين گروهى & \multirow{3}{*}{ 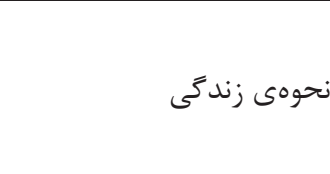 } \\
\hline & & rDT/VAS & 1.9 & rVrqه/rgr & درون گروهى & \\
\hline & & - & $1 \cdot 1$ & $r q \Delta \wedge 9 / \cdot \Delta r$ & كل & \\
\hline \multirow{3}{*}{$\cdot / \cdot r \Lambda$} & \multirow{3}{*}{ T/GFY } & 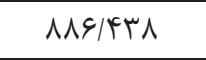 & f & rFGQ/VQT & بين گروهى & \multirow{3}{*}{ تحصيلات } \\
\hline & & rTV/VII & $1 \cdot r$ & MTEYG/DQ. & درون گروهى & \\
\hline & & - & 1.9 & ऍ & كل & \\
\hline \multirow{3}{*}{$\cdot 1 \cdot$} & \multirow{3}{*}{$q / \cdot p q$} & $r \vee \cdot \Delta / V \wedge q$ & r & 1IV/rGV & بين گرووهى & \multirow{3}{*}{ وضعيت تأهل } \\
\hline & & rq৭/IVD & 110 & $M F Y \cdot \Delta / \cdot V G$ & درون گروهى & \\
\hline & & - & 111 & FTATT/FFT & كل & \\
\hline \multirow{3}{*}{.$/ \cdot V T$} & \multirow{3}{*}{$r / T / \Lambda$} & VqY/rqr & f & MIVV/ISV & بين گروهى & \multirow{3}{*}{ رضايت از وضعيت اقتصادى } \\
\hline & & TUN/ITA & $1 \cdot 1$ & rᄉ९VV/AVT & درون گروهى & \\
\hline & & - & 115 & $p \backslash \wedge \Delta \Delta / \cdot r q$ & كل & \\
\hline \multirow{3}{*}{$\cdot 1 \cdot \cdot 1$} & \multirow{3}{*}{ r/gFt } & $99 \cdot / r \cdot r$ & rF & IDAFF/AFT & بين كروهى & \multirow{3}{*}{ دجار بيمارى بودن } \\
\hline & & rYq/VDS & 19 & TKTYNNKGQ & درون گروهى & \\
\hline & & - & 111 & $r \Lambda \cdot V r / l \mid r$ & كل & \\
\hline \multirow{3}{*}{$\cdot|r| T \mid$} & \multirow{3}{*}{$1 / r \Delta \varphi$} & $4 / 9 / 199$ & IV & VITQ/AVV & بين خروهى & \multirow{3}{*}{ مصرف دارو } \\
\hline & & rM/ADr & $\wedge \mathrm{V}$ & $r q \cdot r \Delta / 1 \wedge q$ & درون خروهى & \\
\hline & & - & $1 \cdot r$ & $r G|V| / . q \mu$ & كل & \\
\hline
\end{tabular}


تفاوت در نوع سوء رفتار در مطالعه حاضر با مطالعات ذكر شده

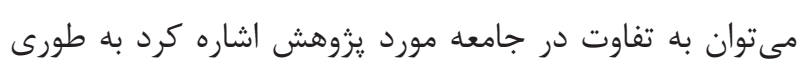

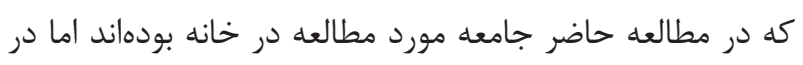

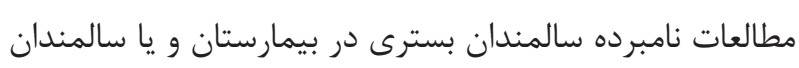
عضو خانه سالمندان مورد بررسى قرار ترفتنه بودند. در بررسى حيطههاى سوء رفتار غفلت عاطفى، شايعترين نوع سوء

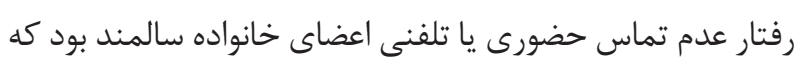

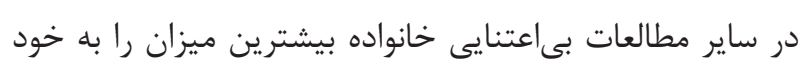

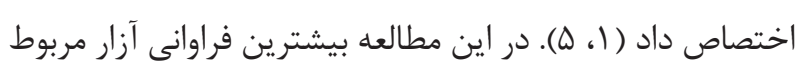

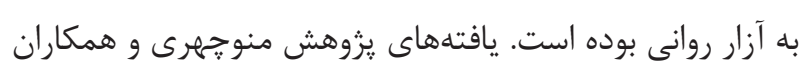
نشان داد / / 1 م درصد از سالمندان غفلت را تجربه نمودهاند ( • (1).

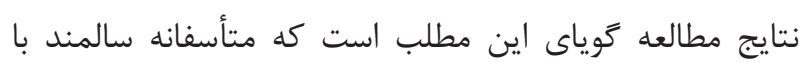

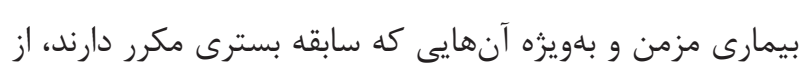

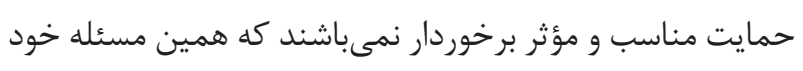

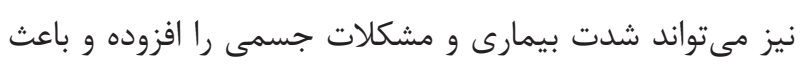

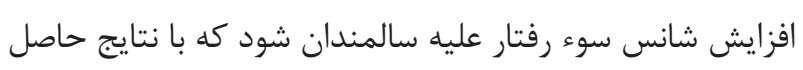

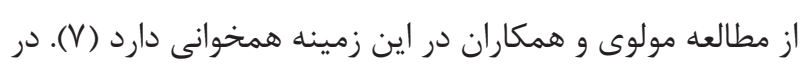

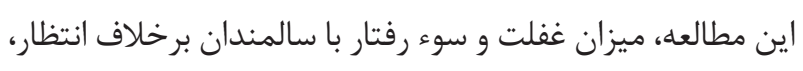
در خيلى از متغيرهاى بررسى شده پايينتر از نقاط ديخر از ايران بوده است كه مىتواند مرتبط با استقلال مالى بيشتر سالمندان اين مطالعه نسبت به ساير مطالعات باشد. در مطالعه حاضر رضايت از زندكى سالمندان همر اه با كاهش سوء

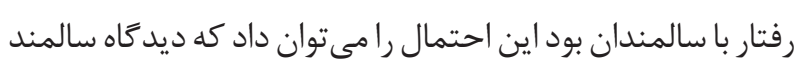

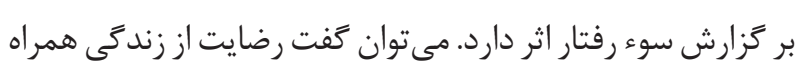
با ديد مثبت از رفتار اطرافيان همراه است و اين سالمندان كمتر از راز سالمند آزارى شاكى هستند. همجنين، سالمندانى كه مورد سوء

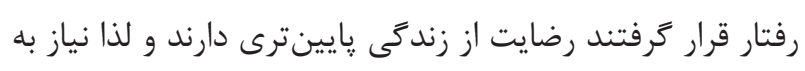

انجام مطالعات مداخلهاى بيشترى است. در ساير نقاط دنيا براى جلوكيرى سوء رفتار مالى قوانين بسيار

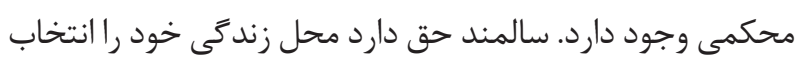

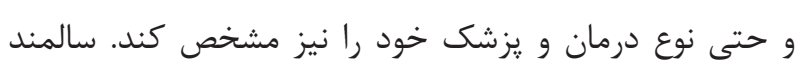

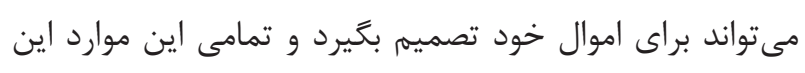

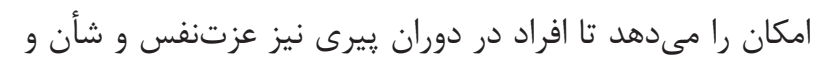
مقام خود را داشته باشند. لازم است در ايران نيز به وضع و دوران بيرى نيز عزتف و ونان

\section{بحث و نتيجه كيرى}

مطالعه حاضر با هدف تعيين ارتباط سالمند آزارى و سوء رفتار

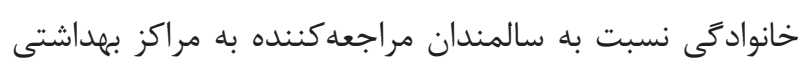

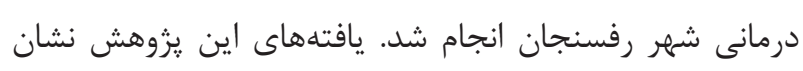

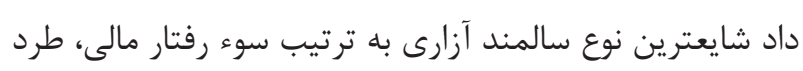

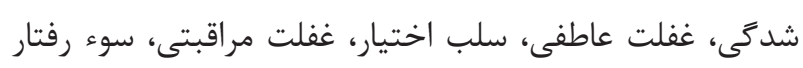
روانشناختى، غفلت مالى و سوء رفتار جسمى بود.

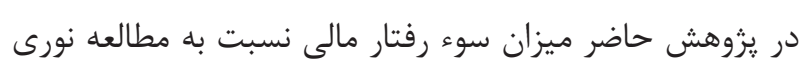

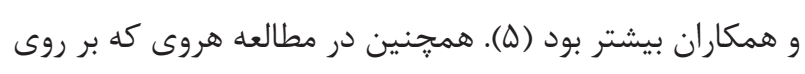
سالمندان عضو كانون هاى جهانديد كمتر بود كه با نتايج مطالعه حاضر همخونوانى ندارد (1). از على على

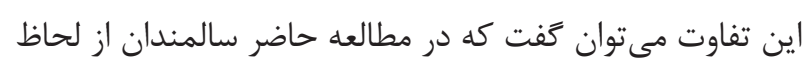
اقتصادى، از وضعيت مالى بهترى برخوردار بودند و همين علت،

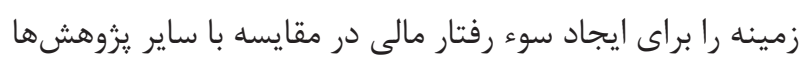
بيشتر كرده است. بر اين اساس مى توان ادعا كرد كه تمكين مالى لئل

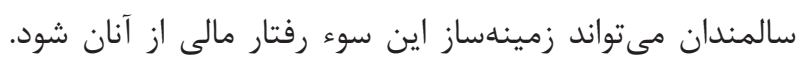

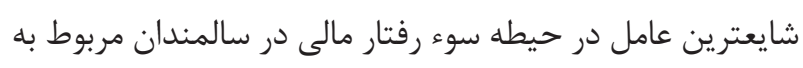
تحميل مخارج زندگى بر دوش سالمند بدون رضايت سالمند بود.

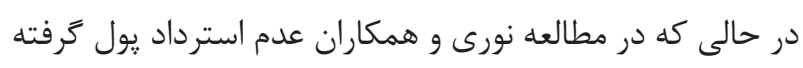

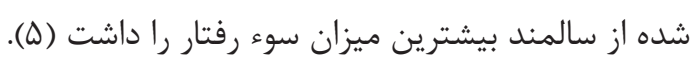

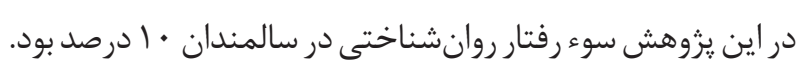

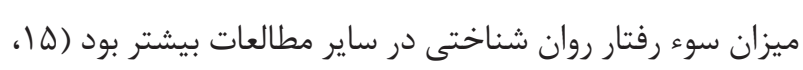

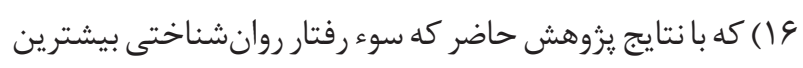

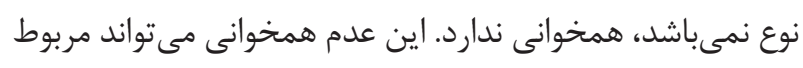

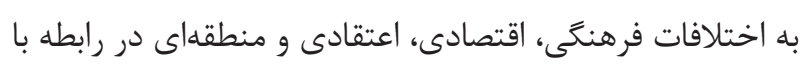
نحوه برخورد و نكهدارى افراد سالمند بين مناطق مختلف و ملل مختلف باشد. در اين مطالعه ميزان سوء رفتار جسمى در سالمندان ب درصد

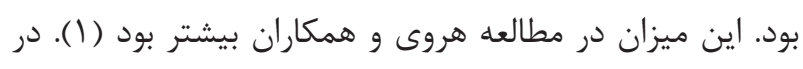

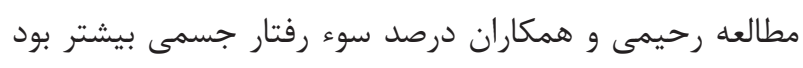

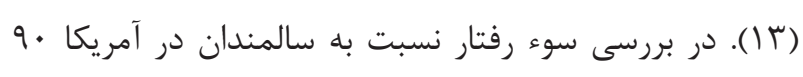

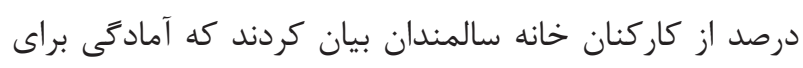

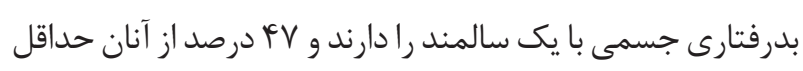

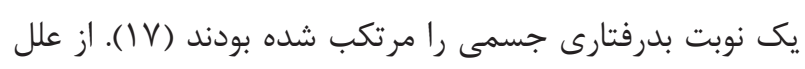




$$
\text { شوند و بتوانند از حقوق خويش دفاع نمايند. }
$$

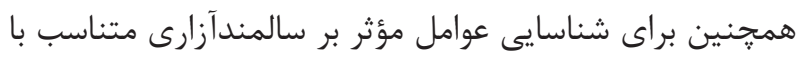

فرهنگ سالمندان، انجام يزوهشهايى با حجم نمونه بالا توصيه

$$
\text { مىشود. }
$$

\section{تشكر و قدردانى}

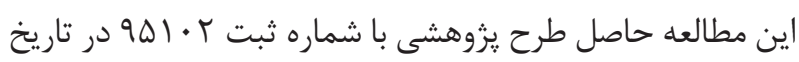

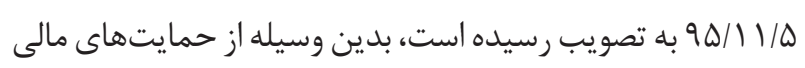
معاونت تحقيقات و فناورى دانشعاه علوم يزشكى رفسنجان و كليه

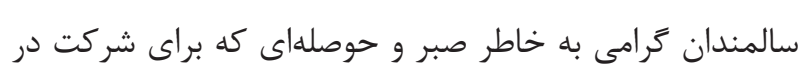
اين مطالعه داشتهاند، تشكر و قدردانى مى كر درد.

تضاد منافع

بدين وسيله نويسند كان تصريح مىنما يند هيجَّ كونه تعارض منافعى براى نويسندكان در اين مقاله وجود ندارد.

\section{References}

1- Heravi Karimoei M, Reje N, Foroughan M, Montazeri A. Elderly abuse rates within family among members of senior social clubs in Tehran. Iranian J Ageing. 2012;6(4):37-50.

2- Cuntril H. The pattern of human concerns. New Brunswick. NJ: Rutgers University Press; 1965.

3- Nassiri H, Heravi Karimooi M, Jouybari L, Sanagoo A, Chehrehgosha M. The prevalence of elder abuse in Gorgan and Aq-Qala cities, Iran in 2013. Iranian J Ageing. 2016;10(4):162-73.

4- Hejazi E, Salehnajafi M, Amani J. The mediating role of intrinsic motivation on the relationship between basic psychological needs and life satisfaction. Contemporary Psychology. 2015;9(2):77-88.

5- Nori A, Rajabi A, Esmailzadeh F. Prevalence of elder misbehavior in northern Iran (2012). J Gorgan Univ Med Sci. 2014;16(4).

6- Ghodoosi A, Fallah Yakhdani E, Abedi HA. Studying the instances of elder abuse and their relationship with age and sex in the hospitalized elderly. Iranian J Forensic Med. 2014;20(1):367-76.

7- Molaei M, Etemad K, Taheri Tanjani P. Prevalence of elder abuse in Iran: a systematic review and meta analysis. Salmand. 2017;12(2):242-53. http://dx.doi.org/10.21859/sija-1202242

8- Wu L, Chen H, Hu Y, Xiang H, Yu X, Zhang T, et al. Prevalence and associated factors of elder mistreatment in a rural community in People's Republic of China: a cross-sectional study. PLoS One. 2012;7(3):e33857. http://dx.doi.org/10.1371/journal. pone.0033857 www.ncbi.nlm.nih.gov/pubmed/22448276

9- Cadmus EO, Owoaje ET. Prevalence and correlates of elder abuse among older women in rural and urban communities in South Western Nigeria. Health Care Women Int. 2012;33(10):973-84. http://dx.doi.org/10.1080/07399332.2012.655394 www.ncbi.nlm. nih.gov/pubmed/22946597

10- Manoochehri H, Ghorbi B, Hosseini M, Oskuyee NN, Karbakhsh M. Degree and types of domestic abuse in the elderly referring to parks of Tehran. Advances in Nursing \& Midwifery. 2009;18(63):43-50.

11- Narimani M, Rostami M. Role of Religious attitudes, Spiritual Well-Being and social support in predicting the life satisfaction in mothers of mental retardation children. Islam And Health Journal. 2014;1(3):41-9.

12- Arshi M, Dalirian S, Eghlima M, Shirinbayan P. The effectiveness of group social work forgiveness intervention on the life satisfaction of the elderly living in care institutions. Iranian J Ageing. 2016;10(4):174-81.

13- Rahimi V, Heidari M, Nezarat S, Zahedi A, Mojadam M, Deris S. Factors Related to Elder Abuse within the Family. J Geriatric Nurs. 2016;3(1):89-100. http://dx.doi.org/10.21859/jgn.3.1.89

14- Tagharrobi Z, Sharifi K, Sooky Z, Tagharrobi L. Psychometric evaluation of the Iranian version of Quality of Life Enjoyment and Satisfaction Questionnaire Short Form (Q-LES-QSF). Payesh (Health Monitor). 2012;11(2):235-44.

15- Heravi-Karimooi M, Anoosheh M, Foroughan M, Sheykhi M, Hajizadeh E. Designing and determining psychometric properties 
of the Domestic Elder Abuse Questionnaire. Iranian J ageing. 2010;5(1):0-.

16- Hamby S, Smith A, Mitchell K, Turner H. Poly-victimization and resilience portfolios: Trends in violence research that can enhance the understanding and prevention of elder abuse. J Elder Abuse Negl. 2016;28(4-5):217-34. http://dx.doi.org/10.1080/08946566.2
016.1232182 www.ncbi.nlm.nih.gov/pubmed/27606781

17- Sung K-T, Kim BJ, Torres-Gil F. Respectfully Treating the Elderly: Affective and Behavioral Ways of American Young Adults. Educational Gerontology. 2010;36(2):127-47. http:// dx.doi.org/10.1080/03601270903058549 